\title{
TENTATIVA DE SUICÍDIO POR INTOXICAÇÃO EXÓGENA ENTRE ADOLESCENTES NO ESTADO DO ACRE
}

\author{
Frankllin Ramon da Silva ${ }^{1}$; Wellington Maciel Melo후 Keyla Millena Lima da Silva Amorim ${ }^{1}$; \\ Deivid Braga da Silva'; Edmilson Pereira Barroso²; Eder Ferreira de Arruda ${ }^{3}$ \\ ${ }^{1}$ Bacharel em Enfermagem, Centro Universitário UNINORTE, Rio Branco, Acre. \\ ${ }^{2}$ Bacharel em Biomedicina, Centro Universitário UNINORTE, Rio Branco, Acre. \\ ${ }^{3}$ Docente, Centro Universitário UNINORTE, Rio Branco, Acre. \\ E-mail: frankllinramondasilva@outlook.com \\ DOI: $10.47094 /$ ICONNACT.2020/23-26
}

\section{RESUMO}

Introdução: A intoxicação exógena é um importante recurso utilizado na tentativa de suicídio entre adolescentes. Objetivo: Descrever o perfil epidemiológico acerca da tentativa de suicídio por intoxicação exógena entre adolescentes no Acre no ano de 2019. Metodologia: Trata-se de um estudo descritivo realizado a partir de dados do Sistema de Informação de Agravos de Notificação que estão disponíveis no site do DATASUS, sendo incluídos todos os casos na faixa etária de 15 a 19 anos. Resultados: Foram registrados 118 casos de intoxicações exógenas em adolescentes, sendo que $63,5 \%$ foram tentativas de suicídio. Destas, 76,0\% ocorreram em jovens do sexo feminino, 73,3\% eram pardos, $41,3 \%$ tinham o ensino médio incompleto e $76,0 \%$ utilizaram medicamentos como meio de tentativa. Considerações finais: As tentativas de suicídio por intoxicação exógena entre os adolescentes se configuram como um importante problema de saúde. Portanto, são necessárias medidas preventivas que visem diminuir o número de casos.

Palavras-chave: Saúde do Adolescente; Epidemiologia; Toxicologia.

\section{INTRODUÇÃO}

A Organização Pan-Americana da Saúde (2020) estima que cerca de 800 mil pessoas a cada ano morrem por suicídio e que o número de tentativas de suicídio seja ainda superior. No ano de 2016, se configurou como a segunda principal causa de morte entre jovens de 15 a 29 anos de idade no mundo. A cada suicídio, há dez tentativas que requerem cuidado médico, proporcionando elevado ônus para a sociedade, desde a desestruturação familiar à grande demanda de recursos públicos destinados a esse evento (GONÇALVES et al., 2011). 
Neste sentido, a intoxicação exógena é um dos recursos mais utilizados na tentativa de suicídio entre os adolescentes que comumente, nessa fase, tem o primeiro contato com bebidas alcoólicas e drogas ilícitas, práticas essas que desencadeiam comportamento depressivo, e consequentemente o desejo de tirar a vida (BATISTA et al., 2018). Além disso, doenças, problemas de relacionamento, bullying e dificuldades financeiras tendem a desencadear a vontade suicida (BOTEGA, 2014).

A intoxicação medicamentosa é a causa que mais se destaca entre os adolescentes, sendo considerado um relevante problema de saúde pública. Estudos nacionais apontam que estes indivíduos têm maior risco de tentativa de suicídio por medicamentos e que mesmo as mulheres estando mais predispostas há aumento dos casos entre os adolescentes do sexo masculino (RIBAS et al., 2018; LÔBO et al., 2020).

Dessa forma, as intoxicações exógenas se caracterizam como o principal meio para tentativas de suicídio entre adolescentes, por isso é de extrema relevância caracterizar os aspectos que envolvem a temática no Acre a fim de que, por meio dos dados apresentados, medidas educativas e de prevenção e promoção a saúde possam ser desenvolvidas.

Diante disso, o presente estudo teve como finalidade descrever o perfil epidemiológico acerca da tentativa de suicídio por intoxicação exógena entre adolescentes no Acre no ano de 2019.

\section{METODOLOGIA}

Foi realizado um estudo observacional descritivo, do tipo transversal, com abordagem quantitativa sobre a tentativa de suicídio por intoxicação exógena entre adolescentes no estado do Acre no ano de 2019.

Os dados foram obtidos durante o mês de novembro de 2020 a partir do Sistema de Informação de Agravos de Notificação (SINAN) e estão disponíveis no site do Departamento de Informática do Sistema Único de Saúde (DATASUS), sendo incluídos todos os casos na faixa etária de 15 a 19 anos.

Foram considerados como casos de tentativa de suicídio, todos os registros classificados pelo diagnóstico que utilizavam os códigos X64 - X64.9 (Autointoxicação por e exposição, intencional, a outras drogas, medicamentos e substâncias biológicas e às não especificadas) do capítulo XX (Causas externas de morbidade e de mortalidade) da Décima Revisão da Classificação Estatística Internacional de Doenças e Problemas Relacionados à Saúde (CID-10).

Os dados foram analisados de acordo com a frequência de notificação, sexo, cor/raça,

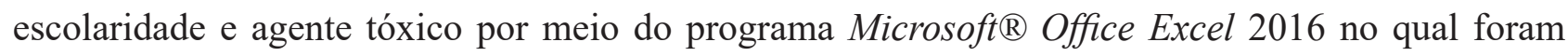
calculadas as frequências absolutas e relativas das variáveis. 


\section{RESULTADOS E DICUSSÃO}

No estado do Acre, no ano de 2019, foram registrados 118 casos de intoxicações exógenas em adolescentes, sendo que $63,5 \%$ das notificações foram tentativas de suicídio por meio de intoxicações intencionais $(n=75)$. Em análise semelhante foram registradas 954 tentativas de suicídios por intoxicação exógena no estado Espírito Santo, entre os anos de 2007 e 2014, na faixa etária de 10 a 19 anos representando $21,4 \%$ do total de tentativas para todas as faixas etárias e com média de aproximadamente 136 casos por ano (COLOSP et al., 2019).

No que diz respeito ao sexo, 76,0\% das notificações de intoxicações ocorreram entre indivíduos do sexo feminino. Este dado está em consonância com estudo nacional realizado por Ribas et al. (2018) que avaliou as tentativas de suicídio por intoxicação exógena na faixa etária de 10 a 19 anos e demonstrou que as mulheres possuem 3 vezes mais risco para tentativa de suicídio quando comparadas aos homens da mesma faixa etária e $74 \%$ mais riscos quando comparadas a mulheres de 20 anos ou mais.

Com relação à cor ou raça, 73,3\% dos casos registrados eram de indivíduos pardos. Semelhantemente, 73,5\% dos registros de suicídio em uma cidade no interior do Ceará nos anos de 2006 a 2015 foram em pessoas pardas (PEDROSA et al., 2018). Essa maior prevalência de tentativas de suicídio por intoxicação também foi observada no estudo de Colosp et al. (2019) no qual pretos e pardos somaram 58,9\% das tentativas de suicídio independentemente da idade.

Concernente à escolaridade, $41,3 \%$ dos adolescentes tinham o ensino médio incompleto. Este resultado pode ser explicado em virtude que os indivíduos nesta faixa etária ainda se encontram em idade escolar. Entretanto, Félix et al. (2016), em sua revisão integrativa, afirmam que baixa escolaridade assim como outros aspectos sociodemográficos são importantes fatores de risco para o suicídio.

No que se refere ao agente tóxico, 76,0\% das tentativas de suicídio ocorreram através de intoxicações por medicamentos. Este valor foi superior ao encontrado no Ceará em que 26,0\% das tentativas de suicídio por adolescente foram por intoxicação medicamentosa, tendo dentro deste valor uma predominância para a faixa etária entre 15 e 19 anos, sobretudo entre estudantes e uma maior associação com o sexo feminino (LÔBO et al., 2020). Em relação às tentativas de suicídio e suicídio por intoxicação em crianças e adolescentes Rosa et al. (2015) faz um alerta para a existência uma complexa rede de fatores que podem leva a facilidade do acesso aos agentes tóxicos por essa população.

\section{CONSIDERAÇÕES FINAIS}

As tentativas de suicídio por intoxicação exógena entre os adolescentes no estado do Acre, 
principalmente, por medicamentos se configuram como uma importante causa externa de morbidade, sobretudo entre as jovens de cor parda. Portanto, é necessário o estabelecimento de medidas preventivas que considerem as características dos indivíduos e que sejam voltadas para redução dos fatores de risco com a finalidade de diminuir o número de novos casos.

\section{PRINCIPAIS REFERÊNCIAS}

BATISTA, M. D. et al. Suicídio em jovens e adolescentes: uma revisão acerca do comportamento suicida, sua principal causa e considerações sobre as formas de prevenção. Rev. Mult. Psic. v.12, n. 40, p. 705-719, 2018.

BOTEGA, N. J. Comportamento suicida: epidemiologia. Psicol. USP, v.25, n.3, p.231-236, 2014.

COSLOP, S. et al. Tentativas de suicídio por intoxicação exógena no estado Espírito Santo, Brasil. Revista Brasileira de Pesquisa em Saúde, v. 21, n. 1, p.46-54, 2019.

FÉLIX, T. A. et al. Fatores de risco para tentativa de suicídio: produção de conhecimento no Brasil. Revista Contexto \& Saúde, v.16, n.31, p.173-185, 2016.

GONÇALVES, L. R. C. et al. Determinantes espaciais e socioeconômicos do suicídio no Brasil: uma abordagem regional. Nova econ, v.21, n.2, p.281-316, 2011.

LÔBO, A. P. A. et al. Attempted suicide by drug intoxication: adolescence on alert. Adolescência e saúde, v.17, n.2, p.42-50, 2020.

ORGANIZAÇÃO PAN-AMERICANA DA SAÚDE. Suicídio. Disponível em: https://www.paho. org/pt/topicos/suicidio. Acesso: 26 nov. 2020.

PEDROSA, N. F. N. C. et al. Análise dos principais fatores epidemiológicos relacionados ao suicídio em uma cidade no interior do Ceará, Brasil. Journal of Health \& Biological Sciences, v.6, n.4, p.399-404, 2018.

RIBAS, A. et al. Tentativa de suicídio por intoxicação exógena na faixa etária de 10-19 anos no Brasil. Caderno de Publicações Univag, v.1, n.09, p.69-74, 2018.

ROSA, N. M. et al. Intoxicações associadas às tentativas de suicídio e suicídio em crianças e adolescentes. Rev Enferm UFPE, v.9, n.2, p.661-668, 2015. 